\title{
Dynamic Response of Saturated Asphalt Pavement under Vehicle Loading
}

\author{
HUANG-Jun ${ }^{1,2, a}$, CAI-Yue ${ }^{1, b}$, DAI Shao-bin ${ }^{1,2, c}$, PAN-Xin ${ }^{1, d}$ \\ ${ }^{1}$ School of Civil Engineering and Architecture, Wuhan University of Technology, Wuhan 430070, \\ China; \\ ${ }^{2}$ Design\&Research Institute, Wuhan University of Technology, Wuhan 430070, China

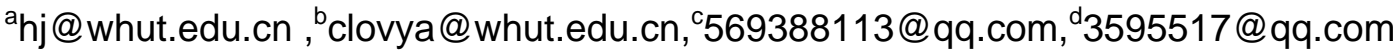

Key words: asphalt pavement; dynamic response; moisture-loading coupling; finite element analysis

\begin{abstract}
The vehicle load action often leads to serious damage of saturated asphalt pavement. The finite element model of saturated asphalt pavement was established by ANSYS to research mechanics behavior of pavement response to moisture-loading coupling action. Then, the spatial distribution of pore-water pressure, vertical displacement and shear stress of saturated asphalt pavement was analyzed. The results indicate that the stress field and displacement field changed a lot, the positive and negative change of pore-water pressure will result in stripping of asphalt mixtures. The vertical displacement variation of each layer structure is basically the same, and the shear stress is mainly concentrated on the area around the intersection of lower layer and grassroots which may result in rutting damage.
\end{abstract}

\section{Introduction}

Asphalt pavement is the main pavement structure type of highway network in China. To be a seamless road, asphalt pavement has many virtues, such as slight vibration, low noise, convenient maintenance and comfortable driving experience. But, the problem of pavement damage is also prominent, especially, the early damage phenomenon. The damage shorten the pavement's service life which may affect the regular service of pavement during design service life ${ }^{[1,2]}$.

The existing conclusions show that water is the key influencing factor of pavement damage ${ }^{[3,4]}$. To the newly built road, if the water in the pavement can not be discharged in time, the seasonal environment temperature and repeated vehicle load may strip aggregate from asphalt pavement and reduce pavement strength which may lead to raveling, potholes, corrugation and other damages.Water damage will bring great potential safety hazard in the process of driving, and consume huge maintenance costs. So, to research the changing rule of the stress field and displacement field of the saturated asphalt pavement under pore water-vehicle load coupling action is necessary to understand the failure mechanism of pavement. And, it also has very vital significance to improve the technical measures and pavement performance, eliminate the early damage and prolong service life.

In the paper, the saturated asphalt pavement under vehicle load is simulated by finite element software ANSYS to research the changing rule of pore-water pressure, shear stress, vertical displacement and other index of the pavement under moisture-loading coupling action. 


\section{The establishment of finite element model}

\subsection{Basic assumption of layered elastic pavement}

Layered elastic pavement is an elastic system composed by some elastic layers and elastic halfspace structure and the asphalt pavement can be classified as layered elastic pavement ${ }^{[5]}$, so, the basic assumptions are as followed:

(1)Each pavement layer is ideal linear elastic elastomer, isotropic and completely obey the generalized Hooke law;

(2) The deformation and displacement are small;

(3) The stress, deformation and displacement of infinity is zero;

(4)Each layer is continuous, seamless, material is uniformly distributed in the whole space;

(5)The initial stress of the object is equal to zero before the external load is applied.

\subsection{Model and boundary conditions}

To guarantee the accuracy of the calculation, avoid a tedious calculation, the paper adopt 2 dimension plane model as the analysis model. As shown in Fig.1, the size of the plane is 3x3m, in structural layer thickness direction, the model from top to bottom are upper layer, mid-surface, lower layer, grassroots, sub-base and subgrade, and their thicknesses are respectively $0.04 \mathrm{~m}, 0.06 \mathrm{~m}, 0.08 \mathrm{~m}, 0.36 \mathrm{~m}, 0.20 \mathrm{~m}, 2.26 \mathrm{~m}$.

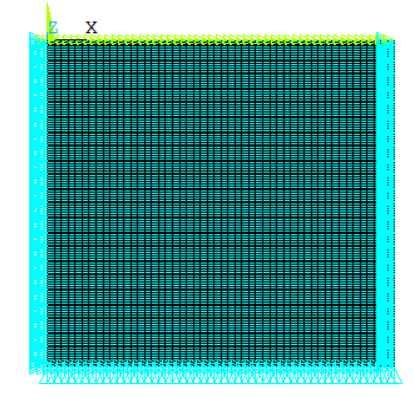

Fig1 Finite element model

Boundary conditions of the model are as follows: the horizontal and vertical direction of lower boundary of the model are fixed and waterproof; the boundary of the model in the horizontal direction has been established, but the boundary can be mobilized in the vertical direction and is waterproof. The upper boundary of the model is established in the horizontal direction but free in the vertical direction. Except the load region, the rest region is permeable.

\subsection{Vehicle load}

The load patterns are manifold, wheel size, tire texture and other influencing factors all will affect the type and size of the load, Due to the circular uniformly distributed load is accordance with the actual situation of ordinary vehicle wheel's incentive. Therefore, according to the current rules and regulations, as shown in Fig.2, the vehicle load is simplified as double circular uniformly distributed vertical load ${ }^{[6]}$.

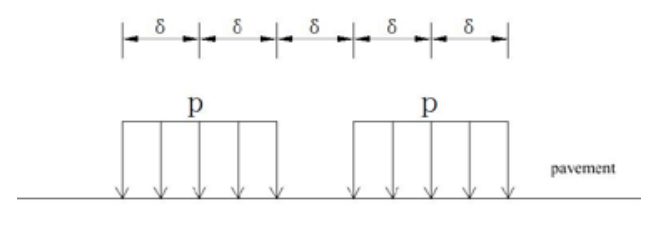

Fig2 Wheel load model

The paper adopted sinusoidal-load to simulate the driving load, the maximum circular uniformly distributed vertical load is $P_{\max }=0.7 \mathrm{MPa}$, the time of the single acting driving is $\mathrm{T}$. During the 
analysis time, the uniformly distributed load value function ${ }^{[7]}$ is as equation (1). The driving speed is $90 \mathrm{~km} / \mathrm{h}$ which is fixed and immovable, the load time is $0.05 \mathrm{~s}$, and the analysis time is $\mathrm{T}=0.25 \mathrm{~s}$.

$$
p=\left\{\begin{array}{lc}
P_{\max } \sin \left(\frac{\pi}{T} t\right) & 0 \leq t \leq 0.05 \mathrm{~s} \\
0 & 0.05 \mathrm{~s} \leq t \leq 0.25 \mathrm{~s}
\end{array}\right.
$$

\subsection{Material parameters of pavement structure}

The high-grade asphalt concrete pavement with three layers is taken as analysis object, in structural layer thickness direction, except the subgrade, the upper layer, mid-surface, lower layer, grassroots, sub-base are composed by cement stabilized macadam or grading macadam, from top to bottom. The density, Poisson's ratio, elastic modulus, saturated permeability coefficient and other parameters of each layer of the pavement structure model are presented in Table1.

Table 1 Parameters of each layer of the structure

\begin{tabular}{|ccccc|}
\hline Name of each layer & Density $/\left(\mathrm{g} / \mathrm{cm}^{3}\right)$ & $\begin{array}{c}\text { Poisson } \\
\text { ratio }\end{array}$ & $\begin{array}{c}\text { Modulus of } \\
\text { elasticity } \\
/ \mathrm{MPa}\end{array}$ & $\begin{array}{c}\text { Saturation permeability } \\
\text { coefficient } \\
(\mathrm{m} / \mathrm{s})\end{array}$ \\
\hline upper layer & 2.64 & 0.30 & 1400 & $4.8 \times 10^{-5}$ \\
mid-surface & 2.55 & 0.35 & 1200 & $1.75 \times 10^{-5}$ \\
lower layer & 2.52 & 0.35 & 900 & $1.25 \times 10^{-5}$ \\
grassroots & 2.2 & 0.20 & 1600 & $1.23 \times 10^{-7}$ \\
sub-base & 2.2 & 0.30 & 350 & $2.65 \times 10^{-4}$ \\
subgrade & 1.65 & 0.40 & 40 & $3.32 \times 10^{-9}$ \\
\hline
\end{tabular}

\section{The vertical distribution of pore-water pressure}

Figure 3, Figure 4 are respectively the equivalent distribution nephogram when pore-water pressure is maximum and the history curves of the maximum pore-water pressure of the central and the bottom surface. As shown in Figure 3, when vehicles passing by, pore-water pressure in saturated pavement structures are mainly distributed in the surface structure.
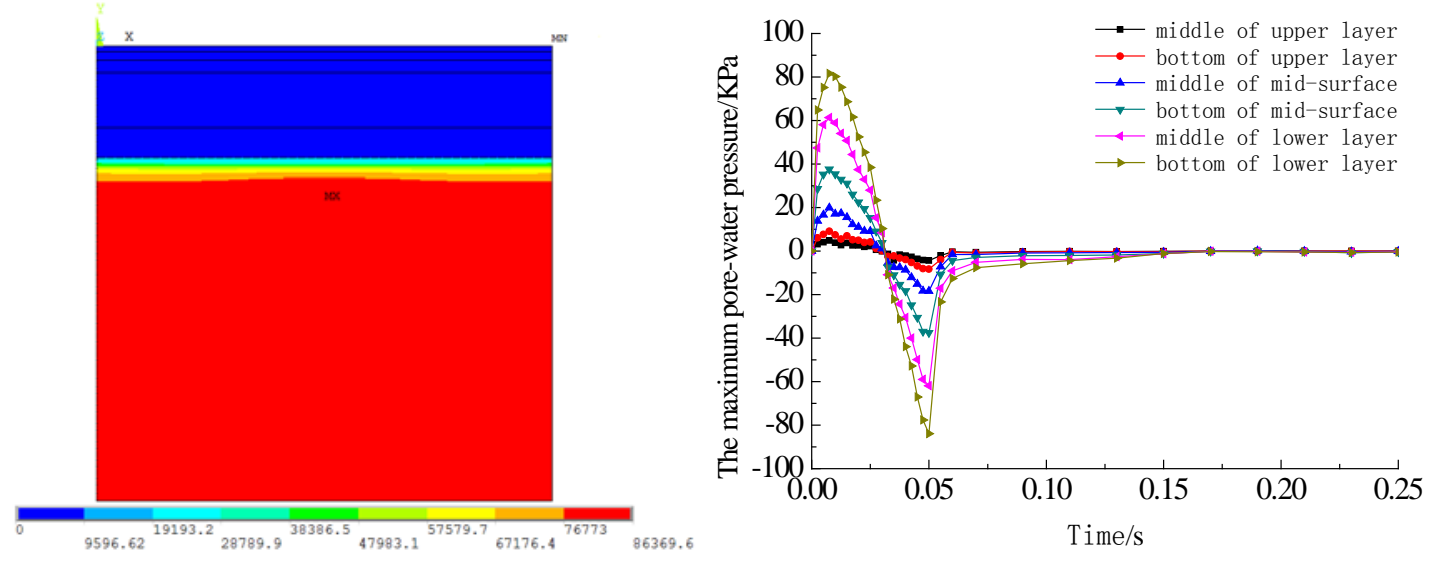

Fig 3 The distribution of maximum pore-water pressure

Fig 4 The history curves of the maximum pore-water pressure

As shown in Figure4, the pore-water pressure in each layer of asphalt pavement structure change with the change of the vehicle load, and change trend is roughly a sinusoid. When time is $0.0075 \mathrm{~s}$, pore-water pressure reaches the maximum positive value, then the pore-water pressure began to fall. When time is $0.025 \mathrm{~s}$, the vehicle load is at the maximum and pore-water pressure drop to zero, during 0.025 to $0.05 \mathrm{~s}$, the load is gradually unloaded, pore-water pressure is negative and gradually 
increase. When time is $0.05 \mathrm{~s}$, pore-water pressure reaches the maximum negative value. At the moment of the unloading, the pore-water pressure decline sharply and drop to zero finally. The maximum pore-water pressure in different surface structures gradually increase from top to down, the maximum positive and negative pore-water pressure value both appear at the bottom of the lower layer, are 81.532 and $83.911 \mathrm{KPa}$ respectively. The minimum pore-water pressure appear in the middle of the upper layer, are 4.7766 and $4.7766 \mathrm{KPa}$.

\section{The distribution of vertical displacement}

Vertical deformation of asphalt pavement structure is an important criterion to judge pavement damage. Figure 5, Figure 6 are respectively equivalent distribution nephograms when the vertical displacement is at maximum and history curves of the maximum vertical displacement of each layer under the load effect.

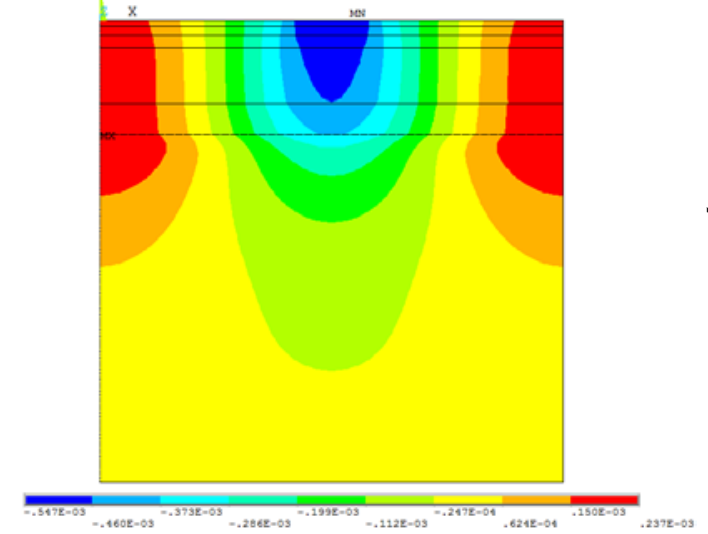

Fig5 The distribution of maximum vertical displacement

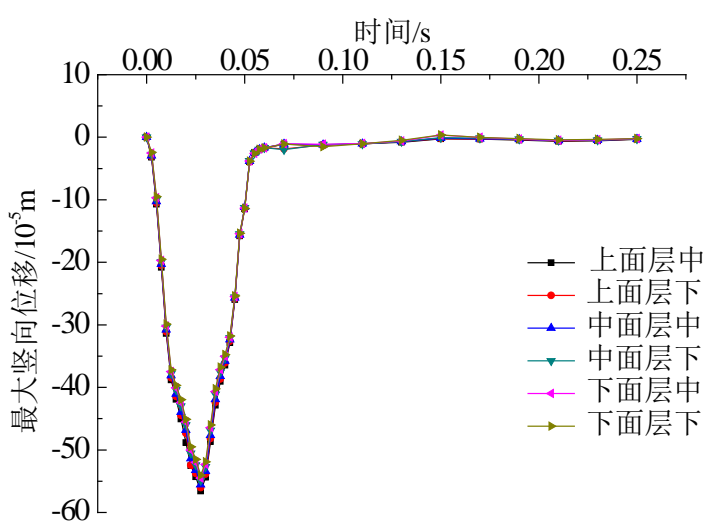

Fig6 The history curves of the vertical displacement

As shown in Figure 6, the vertical displacement of layers gradually increase with the gradual increase of load. But the displacement peak of structure layer does not appear when the load is the biggest $(t=0.025 \mathrm{~s})$, it appear at $0.0275 \mathrm{~s}$ which means that the response of vertical displacement lag behind the load, it is similar to the effect of inertia. When the vertical displacement of the structure reaches the maximum, it will gradually decreases with the decrease of the load, when the load drops to zero $(\mathrm{t}=0.05 \mathrm{~s})$, the vertical displacement gradually approaches to zero. The maximum value of each layer vertical displacement gradually decrease from top to bottom, the maximum displacement of the middle of the upper layer is $56.567 / 0.01 \mathrm{~mm}$, and the maximum displacement of the bottom of lower layer is $54.06 / 0.01 \mathrm{~mm}$, obviously, the gap is not big.

\section{The distribution of the maximum shear stress}

Figure7, Figure 8 are respectively equivalent distribution nephograms when the shear stress of pavement are at maximum and history curves of internal shear stress of the pavement structure under vehicle load action. Shear stress is mainly concentrated on the area around the intersection of lower layer and grassroots under the vehicle load acting surface, and it has an apparent diffusion to sub-base and other area without load action. Shear stress is the main reason that cause pavement cracks and uneven wave. The shear stress of the surface layer increase with the increase of vehicle load, it reaches the peak when $t=0.25 \mathrm{~s}$, then, with the decrease of the load, it gradually drop to zero. The maximum shear stress of the bottom of the lower layer can be up to $229.99 \mathrm{KPa}$, the maximum of the upper layer is about $67.978 \mathrm{KPa}$. Thus, to the area under the grassroots, the shear stress of surface structure is relatively concentrated, when traffic volume is larger, the repeatedly action the driving load may easily lead to road rut, shear cracks etc. Therefore, it is very useful to improve the ability of the shear capacity of surface structure to prevent the destruction of the pavement. 


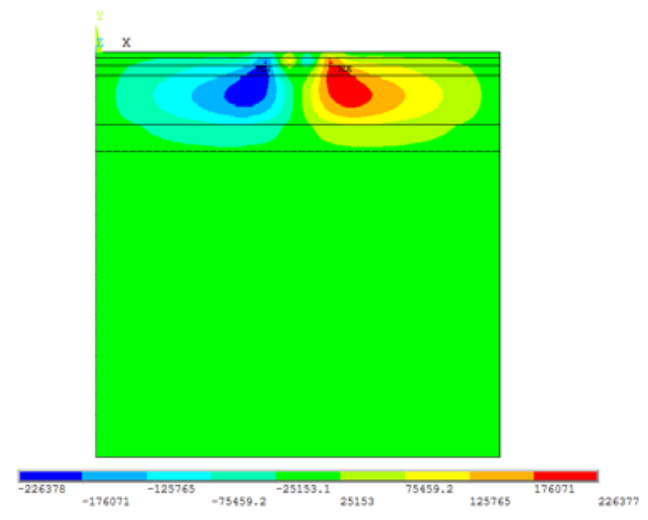

Fig7 The distribution of maximum shear stress

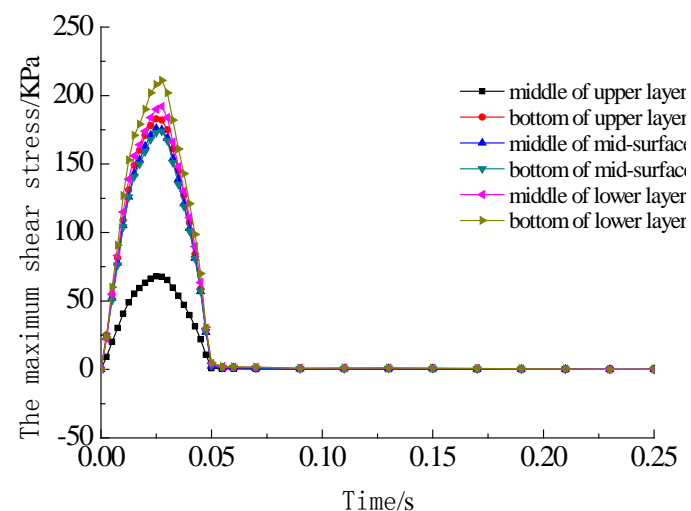

Fig8 The history curves of the shear stress

\section{Conclusion}

In the paper, the finite element mode of the saturated asphalt pavement structure under the vehicle load is built to simulate and analyze the time-history and distribution of pore-water pressure, shear stress and vertical displacement of the pavement structure. Through the analysis of the results, the following conclusions can be drawn:

(1) In the surface structure of the saturated asphalt pavement, the change of pore-water pressure is large and the change trend is a sinusoid, the positive and negative change of pore-water pressure will cause pavement reciprocating scour and extrusion, it makes asphalt mixture bonding strength easy to the lose which may lead to pavement damage.

(2) The change trend of vertical displacement of the pavement structure is roughly the same as the loading regularity of vehicle load, but the change of displacement lag behind the application of vehicle load, the displacement peak appears after the peak of vehicle load, it is similar to the inertial effect. When the vehicle load is unloaded, pavement deformation will slowly disappear.

(3) Shear stress is mainly concentrated on the area around the intersection of lower layer and grassroots under the vehicle load acting surface and it has an apparent diffusion to sub-base and other area without load action. The change of shear stress is consistent with the changes of the load. The shear stress leads to pavement rutting, therefore, some measures should be taken to ensure the strength of the pavement structure during design and construction.

\section{Acknowledgements}

This material is based upon work supported by the open subject foundation (grant no. DQJJ201301) of the Key Laboratory of Road Bridges and Structural Engineering of Hubei Province (Wuhan University of Technology).

\section{References}

[1]SUN Li-jun. Structural Behavior Study for Asphalt Pavements [M]. Shanghai: Tongji University Press. 2003.

[2]SHA Qing-Lin. Premature Damage and Its Preservative Measures of Bituminous Pavement on Expressway [M]. Bejing: China Communications Press. 2001.

[3]XUE-Qiang, SHENG-Qian. Multi-field Coupling Effects and Control Technology of Asphalt Pavement Damage [M].Beijing: Science Press.2009.

[4]XU-Bin. The Theory and Practice of Porous Asphalts [M]. Beijing: China Communications Press. 2011.

[5]CAO Dong-wei, LIU Qing-quan, TANG Guo-qi. Porous Asphalt Pavement [M]. Beijing: China Communications Press. 2010. 
[6]SHA Ai-min. Road Subgrade and Pavement Engineering [M]. Beijing: Higher Education Press. 2011.

[7]DONG Ze-jiao, CAO Li-ping, TAN Yi-qiu. Spatial Distribution of Dynamic Response for Saturated Asphalt Pavement [J]. Journal of Chongqing Jianzhu University. 2007. 